\title{
BUDAYA JURNALISTIK DI METRO TV
}

\author{
Oji Kurniadi \\ Fakultas Ilmu Komunikasi Unisba
}

\begin{abstract}
ABSTRAK
Penelitian ini mengangkat tentang budaya jurnalistik yang terjadi di televisi berita Metro TV. Budaya jurnalistik yang dimaksud adalah suatu proses yang memusatkan perhatian pada masa lalu dan representasi kesinambungan sejarah maupun inovasi dalam nilai, praktik dan kebijakan jurnalistik yang dimunculkan melalui sisi ideologis dan pola pemberitaan sejak proses pencarian, pengumpulan, pengolahan sampai penyajian berita. Beberapa temuan penting dari penelitian ini adalah (1) Metro TV telah menjadi Top of Mind sebagai sumber informasi utama bagi pencari berita, (2) masih kuatnya kepentingan pemilik dalam mewarnai isi berita berkaitan dengan suksesi menuju RI-1 tahun 2014, (3) Berita kekerasan masih mendominasi pemberitaan dalam televisi karena merupakan kondisi nyata yang ada dalam masyarakat Indonesia saat ini, (4) Metro TV berkomitmen untuk mengurangi tayangan-tayangan tersebut dan akan lebih memberikan solusi dan penjelasan duduk perkara suatu peristiwa, (5) Banyaknya pelanggaran etika dalam pemberitaan di Metro TV menunjukkan pengawasan internal belum dilakukan secara maksimal, (6) Cameraperson merupakan filter pertama dalam menyeleksi gambar yang patut atau layak ditayangkan.
\end{abstract}

Kata kunci: Budaya Jurnalistik, Televisi Berita, Program Berita, Berita Kekerasan, Pelanggaran Etika

\section{JOURNALISM CULTURE IN METRO TV}

\begin{abstract}
This research focused on journalism culture existing in Metro TV. Journalism culture here is a process in which attention are weighed toward the past. It is also a representation of both history of sustainability and innovation on values, practice, and journalism policy. Those appears on its ideological aspect and pattern of news from searching, collecting, processing to broadcasting of news. Some results from this research are: (1) Metro TV becomes the Top of Mind for main information sources; (2) Owner's interest appeared to be strongly related with presidential election in 2014 can be looked at its news content; (3) Violence related news is still dominating television as such situation is existed in Indonesia; (4) Metro TV has committed to reduce those kind of programs and promised to give solutions and explanations concerning on particular problems; (5) A lot of ethical violations in Metro TV's news has pointed out to the lack of internal control; (6) The first filter in selecting appropriate pictures to be broadcast lies on the hands of cameraperson.
\end{abstract}

Keywords: Journalism Culture, News Television, News Program, Violence-Content-News, Ethical Violation

Korespondensi: Oji Kurniadi, Drs., M.Si. Fakultas Ilmu Komunikasi Universitas Islam Bandung, Jalan Tamansari no.1 Bandung 40116. Email: ziekurnia@yahoo.com 


\section{PENDAHULUAN}

Televisi merupakan media paling berpengaruh pada kehidupan manusia. Hampir setiap rumah memiliki televisi bahkan bisa lebih dari satu jumlahnya. Kepemilikan pesawat televisi juga semakin meningkat.

Survei menunjukkan media televisi sangat digemari oleh masyarakat tidak saja di Indonesia tapi di seluruh dunia. Survei Nielsen Indonesia, pada kuartal ketiga 2011, rata-rata mereka menghabiskan waktu 4,5 jam setiap harinya untuk menonton televisi dengan pilihan program yang paling diminati adalah program informasi seperti talkshow, majalah televisi, infotainment atau dokumenter sebanyak 26\%, jauh lebih tinggi dibanding periode yang sama tahun lalu, yang persentasenya hanya 15 persen.

Sejarah pertelevisian Indonesia mulai akhir tahun 1962 dengan lahirnya TVRI milik pemerintah. Tahun 1989 dengan mengacu pada SK Menteri Penerangan No. 190/Kep/1987 Oktober 1987 tentang ijin pembukaan saluran stasiun televisi swasta, muncul RCTI (1989), SCTV (1990), TPI (1991), AN-Teve (1993), Indosiar (1995), Metro TV (2000), TV 7 (2001), Trans TV (2002), Global TV (2002), TV One (2008). Hadirnya televisi swasta ini disambut oleh pers Indonesia sebagai alternatif yang akan memperbaiki kualitas dan tayangan TVRI (Kitley, 2001: 268).

Layar televisi Indonesia dipenuhi oleh ratusan program jurnalistik yang isinya relatif berseberangan antara isu-isu aktual yang terkait kepentingan publik seperti bencana banjir, gempa, tsunami, dan kelaparan dengan isu-isu privat seperti skandal seks, korupsi dan perilaku menyimpang lainnya di kalangan selebritis politik dan hiburan. (Masduki, 2008: 158)

Berdasarkan survei Nielsen Audience Measurement di sepuluh kota besar di Indonesia periode Januari-Maret 2010:

“...porsi tayang berita di 11 stasiun tv nasional mencapai $21 \%$ dari total durasi tayang televisi yang mencapai $23.760 \mathrm{jam}$ atau sekitar 4996 jam. Jumlah yang paling besar dibandingkan dengan hiburan (19\%), film (16\%), informasi (14\%) atau serial (12\%)". (Nielsen, 2010)

Besarnya persentasi tersebut karena adanya kontribusi dari program-program berita dari Metro TV dan TV One.

Di tengah-tengah kegembiraan munculnya televisi-televisi baru di Indonesia dengan aneka ragam acaranya ada fenomena menarik yang dapat penulis simak bahwa seringkali terjadi pengulangan berita antara TV satu dengan TV yang lainnya. Seakan-akan tidak ada informasi baru kendati angle berbeda, ada sebuah pola baku yang seragam hampir pada seluruh media massa terutama televisi dalam menyajikan pemberitaan, seringkali media terjebak pada desain informasi yang berulang dan basi pada episode yang sama. Fenomena lainnya adalah adanya ketidakadilan yang dirasakan dalam jurnalistik televisi karena sebagian besar liputan pemberitaan di stasiun televisi swasta berasal dari peristiwa yang terjadi di kota besar khususnya Jakarta dan sekitarnya.

Penelitian disertasi ini mengasumsikan media massa khususnya televisi dalam menyajikan program pemberitaan mengarah pada trendtrend tertentu dengan pola-pola tertentu yang dipengaruhi secara politik ekonomi, organisasi bahkan kultural. Peneliti tertarik ingin mengkaji lebih jauh tentang bagaimana budaya jurnalisme yang telah terbentuk di televisi sebagai media pemberitaan.

\section{METODE PENELITIAN}

Metode yang digunakan dalam penelitian ini adalah metode kualitatif. Penulis melakukan analisis berdasarkan paradigma kritis dengan pendekatan cultural studies (Studi Kultural). Dalam pandangan mazhab kritis, terutama dalam studi-studi yang dikembangkan oleh Centre For Contemporary Cultural Studies, Birmingham University, media massa selalu dirasakan sebagai alat yang "powerful" dan ada ideologi dominan didalamnya. Kualitatif kritis dipilih karena mempunyai ciri kritis, radikal dan ideologis. Teori kritis mengungkap bahwa realitas itu sendiri tidak hanya persoalan luar saja tetapi juga menyangkut sebab dan kondisi yang ada di dalam, yang mungkin tidak dipahami secara memadai dengan generalisasi empiris (Ritzer \& Smart, 2011: 354). "Kajian budaya jelas menggunakan metode kualitatif" (Ratna, 2010: 42). 
Pendekatan Kultural melihat proses produksi berita sebagai mekanisme rumit yang melibatkan faktor internal media sekaligus juga eksternal di luar media. Mekanisme rumit itu ditunjukkan dengan bagaimana perdebatan yang terjadi di ruang redaksi, dimana setiap media mempunyai aturan atau pola sendiri, tetapi disisi lain tidak bisa lepas dari kekuatan-kekuatan ekonomi politik yang berada di luar media.

Berdasarkan kerangka studi budaya budaya jurnalisme mewujud dalam bentuk norma-norma berupa simbol bersama dan kemudian menjadi simbol budaya.

\section{HASIL DAN PEMBAHASAN}

Mengenai Ideologi Metro TV, Jacob Oetomo mengemukakan bahwa "Jurnalisme televisi itu di Indonesia merupakan sesuatu yang baru (1989) dimulai dengan adanya RCTI, tetapi jurnalisme tv tidak pernah dirumuskan dan tidak pernah dikembangkan, tetapi jalan saja mengikuti waktu". Berita RCTI tidak mempunyai kedalaman, tidak pernah menempatkan dalam konteks sehingga kalau bicara budaya jurnalistik di televisi memang tidak ada, karena yang berkembang yang penting ramai dan menarik di dalam show dan tidak menarik dalam substansi.

Budaya Jurnalistik di Metro TV pada masa awal tidak begitu jelas karena banyak ditangani oleh orang-orang pindahan dari SCTV yang orientasinya show. Jadi meskipun dalam visi misinya ikut dalam pembangunan demokrasi di Indonesia dan sebagainya, tidak mengakar pada apa landasan yang sesungguhnya diperjuangkan.

Masuknya Suryopratomo tahun 2008 bisa disebutkan telah membuat wajah Metro TV menjadi lebih baik. Kalau sebelumnya Metro TV dikelola oleh orang-orang yang berbasis hiburan. Berdasarkan pengalamannya bertahun-tahun di Harian Kompas (terakhir sebagai Pemimpin Redaksi), ia mencoba menterapkannya di Metro TV.

Metro TV melakukan re-definisi ulang tentang visi dan misinya serta tujuan didirikannya pada tahun 2010 dengan melibatkan konsultan. Perlu waktu selama 2 tahun untuk meyakinkan seluruh stakeholder, bahwa Metro TV bisa maju kalau punya orientasi dan ideologi yang jelas. Kurang lebih 1200 mengikuti semacam proses re-training untuk memahami apa yang disebut dengan "knowledge to elevate".

Perubahan paling menonjol adalah sistem organisasi, dengan munculnya kompartemen-kompartemen, ada desk hukum, ekonomi, olahraga, internasional, sosial budaya. Kompartemen ini memerlukan waktu satu tahun dan baru 1 Januari 2011 kompartemen itu jalan.

Berdasarkan perubahan-perubahan tersebut, Metro TV mempunyai ideologi sesuai dengan visi yang dimilikinya yaitu "Untuk menjadi stasiun televisi Indonesia yang berbeda dengan dan menjadi nomor satu dalam program beritanya". Adapun misinya salah satunya adalah "Untuk membangkitkan dan mempromosikan kemajuan Bangsa dan Negara melalui suasana yang demokratis, agar unggul dalam kompetisi global, dengan menjunjung tinggi moral dan etika".

Sesuai dengan pendapat dari Idi Subandy yang mengatakan bahwa "Metro TV sepertinya ingin memposisikan diri sebagai TV berkualitas dalam hal berita dan acara dokumenternya". ${ }^{1}$

Positioning sebagai televisi berita tersebut, menjadikan Metro TV sebagai Top of Mind sebagai sumber informasi bagi pencari berita. Model pemberitaan di Metro TV juga menjadi trend setter bagi televisi-televisi swasta lainnya.

Penayangan aktivitas politik dari pemiliknya (Nasional Demokrat) membuat seolah-olah Metro TV merupakan official TV Nasdem. Di sisi lain Metro TV seringkali mengkritik kebijakan-kebijakan pemerintah dan pelaku-pelaku politik tertentu dibandingkan dengan keberhasilan yang dicapai dalam program-program acaranya baik program berita maupun program lainnya. Kondisi ini mau tidak mau menyeret Metro TV sebagai televisi berita yang tidak netral.

"Metro TV juga membawa beban sebagai media pengusaha atau politisi tertentu yang membawa bias kepentingan bisnis dan politik..". ${ }^{2}$

Melalui Direktur Pemberitaannya Metro TV, menganggap hal tersebut merupakan sah-sah saja, tetapi dia menjamin bahwa Metro TV tidak mau terjebak dalam sikap-sikap partisan dan tidak independen karena Metro TV yang dibangun dengan susah payah dan sudah diteri-

1 Wawancara dengan Idi Subandy, 28 November 2011

2 Wawancara dengan Idi Subandy, 28 November 2011. 
ma masyarakat tiba-tiba eksistensinya diambil alih oleh stasiun televisi yang lain. Lebih lanjut Suryopratomo mengatakan "sebagai seorang profesional yang masih punya hati nurani, kalau Metro TV tidak lagi bersikap netral, maka ia akan menjadi orang pertama yang meninggalkan Metro TV.

Pilihan menjadi stasiun berita juga memberi konsekuensi terhadap jumlah pemirsa yang tidak banyak, karena mayoritas demografis masyarakat Indonesia berada C, D dan E. Pemirsa yang disasar Metro TV adalah di level A \& B yang jumlahnya hanya 34\%. Padahal dengan makin banyaknya TV berbayar akan membuat target audiennya tersebut semakin kecil saja, karena target audiennya Metro TV sama dengan audiennya TV Berbayar.

Akibat dari kecilnya penetrasi tersebut berimbas terhadap pendapatan iklan yang diperoleh, padahal pendapatan iklan ini adalah sesuatu yang penting dalam pendanaan di televisi swasta, karena bisa mencapai $60 \%$ - 70\% dari jumlah seluruh anggaran.

Sementara Sandi, mantan produser Metro Hari Ini menyatakan bahwa pendapatan Metro TV melalui share dan rating memang rendah, tetapi Metro lebih memilih indeks yaitu sebuah analisa yang lebih mencerminkan tingkat efektivitas sebuah program dalam menjangkau segmen penonton yang diinginkan. Kalau dalam program biasa iklan hanya Rp. 4 juta/30 detik, maka iklan dalam program Editorial nilainya mencapai Rp. 85 juta/5 menit.

Mengenai representasi nilai-nilai budaya dalam berita Metro TV, "Bad news is good news", telah membuat berita di layar-layar televisi kita dihiasi dengan berita kasus korupsi, radikalisme, terorisme, egosentrisme, kekerasan fisik atau seks, anarkhisme seperti tawuran, kasus pilkada atau praktik-praktik yang menyimpang lainnya. Masyarakat sulit menemukan peristiwa-peristiwa yang mencerminkan karakter asli Indonesia di berita-berita tersebut, sepertinya rasa ke-Indonesia-an kita telah luntur dan menjadi bangsa yang sudah kehilangan jati dirinya. Persoalannya adalah persepsi masyarakat yang cenderung melihat segala ketidakberesan itu telah dianggap sebagai bagian dari budaya Indonesia dan mengesankan betapa buruk wajah negeri kita.

Sifat-sifat positif bangsa Indonesia seperti ramah pada tamu; berhati lembut dan suka damai; kemesraan hubungan antar manusia; punya rasa humor yang baik; dan sabar seolah-olah hilang apabila melihat peristiwa-peristiwa kekerasan dan sebagainya yang muncul di layar kaca. Berita di televisi memang berdasarkan pada fakta. Persoalan yang terjadi fakta yang layak jadi berita adalah fakta yang cenderung merupakan peristiwa negatif, seperti kejahatan atau ketidaksesuaian dengan berbagai aturan. Ada memang fakta bernilai berita yang cenderung positif, seperti capaian keberhasilan sebuah program atau seremonial, seperti keberhasilan para pelajar Indonesia dalam berbagai kegiatan Olimpiade Internasional atau keberhasilan anak-anak bangsa lainnya di bidang olahraga, seni dan sebagainya, tetapi kurang mendapatkan porsi yang besar.

Menurut Schrijvers kekerasan bagian tak terpisahkan dari kapitalisme, sementara dalam pandangan Salmi (2003) "Modus operandi kekerasan yang dijalankan oleh kapitalisme bisa dibedakan menjadi empat macam: kekerasan langsung (direct violence), kekerasan tidak langsung (indirect violence), kekerasan represif (repressive violence) dan kekerasan alienatif (alienating violence)" (Sunarto, 2009: 47).

Berita di Metro TV tidak luput dari masalah yang sama, apalagi sebagai stasiun televisi yang sebagian besar program yang ditawarkan adalah berita. Menanggapi permasalahan tersebut Suryopratomo mengatakan bahwa:

Saya pertama kali datang ke sini, temanteman selalu beranggapan karena Metro TV pernah dipegang oleh orang eks SCTV, kita tahu di SCTV ada program Buser, orang ditangkap sama polisi, itu kan ratingnya paling tinggi. Kriminalitas, darah dan kekerasan itu adalah program yg ratingnya tinggi”.

Oleh sebab itu Metro TV ingin mengulang sukses yang sama dengan SCTV, tetapi Suryopratomo melanjutkan bahwa: "BBC tidak pernah menayangkan darah dan mayat, tetapi orang mengikuti berita itu tanpa ada darah dan mayat, bisa kok, kenapa kita tidak?"3.

Suryopratomo mengakui bahwa membangun kebiasaan menjadi kesadaran baru itu tidak mu-

3 Wawancara dengan Suryopratomo (Direktur Pemberitaan Metro TV) tanggal 12 Juni 2012. 
dah dilakukan. Kita harus lakukan berkali-kali secara intens merubah kebiasaan tersebut.

Sementara Makroen Sanjaya (Wakil Pemimpin Redaksi Metro TV) punya jawaban bahwa: "Semuanya kembali kepada parameter news value itu sendiri karena itu menjadi patokan utama. Aturan selanjutnya adalah Kode Etik Jurnalistik". 4

Direktur Pemberitaan Metro TV Suryopratomo dalam ulang tahun Metro TV ke-10 mengatakan bahwa "pihaknya tidak lagi menampilkan kekerasan dan darah, tetapi akan lebih memberi solusi, sekaligus menjelaskan duduk perkara suatu peristiwa". ${ }^{5}$ Implementasi dari kebijakan itu adalah dihapusnya beberapa program lama dan munculnya program-program baru seperti wideshot yang bernuansa citizen journalism, serta penempatan tayangan kekerasan pada program-program acara yang ditayangkan di atas jam 10, seperti dalam program Buletin Metro Malam.

Tayangan Metro TV juga menampilkan berbagai program acara untuk membangkitkan dan mempromosikan kemajuan Bangsa dan Negara melalui suasana yang demokratis, agar unggul dalam kompetisi global dengan menjunjung tinggi moral dan etika. Beberapa program yang bersifat edukasi, seperti: Editorial Media Indonesia, Kick Andy, Metro Realitas, Suara Anda, dan beberapa program budaya seperti: Expedition, Oasis, Journalist On Duty, dan Lestari.

Metro TV juga mempunyai komitmen untuk tidak menayangkan program infotainment atau program misteri/mistik/supranatural, kecuali mistik dan supranatural yang merupakan bagian dari suatu pertunjukkan seni dan budaya asli/etnik bangsa Indonesia.

Dalam implementasi nilai-nilai etika, pemberitaan juga harus memperhatikan etika. Etika adalah standar perilaku dan pertimbangan moral atau secara sederhananya refleksi tentang pertanyaan-pertanyaan yang terkait dengan benar dan salah, baik dan buruk, harus dan tidak harus.

Berkaitan dengan etika ada beberapa konsep yang menjadi standar perilaku jurnalistik. Konsep tersebut diakui secara universal yaitu akurasi, objektivitas, adil dan berimbang, larangan terhadap pemalsuan informasi, kebenaran,

$4 \quad$ Wawancara dengan Makroen Sanjaya (Wapemred Metro TV) tanggal 8 Juni 2011.

5 www.metrotvnews.com integritas sumber serta menghindari konflik kepentingan.

Kode etik merupakan parameter yang mengatur kegiatan-kegiatan dalam proses pemberitaan di media massa. Selain Kode Etik Jurnalistik masih banyak aturan atau perundangan yang berlaku seperti Etika dan standar penyiaran dalam Undang-Undang Penyiaran No. 32 Tahun 2002, Peraturan KPI No. 02/P/KPI/12/2009 tentang P3, serta Peraturan KPI No.03/P/ KPI/12/2009 tentang SPS.

Pelanggaran yang sering terjadi dalam tayangan berita umumnya meliputi: 1) penyebutan identitas anak di bawah umur, 2) Penayangan gambar yang sadis secara vulgar, 3) Penyajian kekerasan fisik dan seksual dengan jelas, 4) Rekonstruksi ulang secara runtut yang dapat menimbulkan trauma dan ketakutan bagi masyarakat, 5) Penyebutan identitas dengan jelas atas seseorang yang belum jelas statusnya.

Menurut Idi Subandy "Dalam beberapa hal, televisi cukup sering melanggar etika, melecehkan logika penonton, dan meremehkan kalangan bawah". ${ }^{6}$ Lebih lanjut dia mencontohkan tentang "berita korupsi yang melibatkan kalangan atas dan pelaku manipulasi uang, tanpa kedalaman dan mengabaikan prinsip jurnalisme yang baik, sehingga lebih banyak sensasi ketimbang mencari solusi". ${ }^{7}$

Menyangkut tentang tindakan kekerasan, kejahatan dan sensasi dalam tayangan berita televisi, semua aturan atau kode etik menyebut hal itu sama sekali tidak dibenarkan. Tetapi masalahnya televisi mempunyai asumsi yang sangat penting. "Tayangan-tayangan tersebut masih dapat dibenarkan jika kepada khalayak dijelaskan bahwa kejahatan itu tidak pernah menguntungkan, tindakan itu pasti dihukum, dan moral sosial yang dapat diterima akan berlaku dengan sendirinya". (Rivers, 1994: 345)

Metro TV sebagai salah satu stasiun televisi yang menempatkan berita sebagai pilar utama dalam tayangannya, terikat dengan berbagai aturan atau perundangan yang berlaku seperti Etika dan standar penyiaran dalam UU Penyiaran No. 32 Tahun 2002, Kode Etik Jurnalistik, PeraturanKPI No. 02/P/KPI/12/2009 tentang P3, serta Peraturan KPI No.03/P/KPI/12/2009

6 Wawancara dengan Idi Subandy, 28 November 2011.

7 Wawancara dengan Idi Subandy, 28 November 2011. 
tentang SPS dan peraturan sendiri sebagaimana diatur dalam Style Book Metro TV dan panduan Kebijakan dan Standar Berita.

Metro TV mengakui dirinya juga dihadapkan pada dilema. Di satu sisi, dihadapkan pada keniscayaan atau kebutuhan untuk memberitakan konflik, kekerasan, tragedi secepat dan selengkap mungkin untuk memberikan gambaran yang sesungguhnya kepada khalayak. Pilihan ini mengandung resiko media akan dituduh memperunyam keadaan (conflict intensifier).

Di sisi lain, media dihadapkan pada tuntutan berbagai pihak untuk turut menciptakan kondisi yang kondusif untuk menyelesaikan konflik (conflict diminisher). Memenuhi harapan ini mengandung resiko media harus menyeleksi bahkan menutupi fakta-fakta yang dianggap sensitif bagi kelompok-kelompok tertentu.

Solusi yang sering dikedepankan dalam hal ini adalah "jurnalisme damai". Jurnalisme damai adalah bukan saja merupakan cover both sides (dua arah) tetapi juga all both side. Jurnalisme damai lebih mementingkan empati kepada korban-korban konflik daripada liputan kontinyu tentang jalannya konflik itu sendiri.

Beberapa kasus yang terjadi di Metro TV antara lain munculnya gambar adegan video porno dalam sebuah razia video porno di warung internet di daerah Trenggalek, Jawa Timur pada tanggal 14 Juni 2010 pukul 05.00 dalam program Headline News Metro TV, tayangan program berita "Breaking News" MetroTV tanggal 14 April 2010, yang menayangkan bentrokan antara warga dengan Satpol PP di sekitar makam Mbah Priok, program Metro Siang menayangkan kemasan obat kuat yang menampilkan gambar orang berhubungan seks dan dialog interaktif mengenai permasalahan seksualitas secara vulgar dengan salah satu pemirsa melalui telepon, dan menurut Suryopratomo (Direktur Pemberitaan Metro TV) "saat ini di Metro TV marak kembali masalah suap, dimana jurnalis menerima amplop atas peliputan yang dilakukan.

Munculnya berbagai kasus tersebut menunjukkan bahwa pengawasan internal yang dilakukan masih kurang maksimal. Sementara Suryopratomo (Direktur Pemberitaan Metro TV menanggapinya dengan mengatakan: "Kembali lagi, pekerjaan media tidak pernah ada yang sempurna. Media itu karena kecepatannya, selalu berpotensi salah. Masalahnya apakah itu kesalahan profesional yang disengaja atau tida$\mathrm{k}$ ?.

Mengenai cara editor dalam mengidentifikasi berita yang layak ditayangkan, berita itu layak/ tidak layak sangat ditentukan oleh faktor-faktor dalam penyajian sebuah berita, yaitu: ketepatan (akurat), keadilan, kebenaran berita dan objektivitas. M Djen Amar (1984) yang menyebut bahwa dalam kualitas suatu berita harus mengandung unsur-unsur: ketepatan (accuracy), objektivitas (objective), berimbang (balance), singkat dan jelas (concise and clear) dan aktual (recent). Sementara CJ. Westerthal menyebut, penyajian laporan atau berita secara objektif harus mencakup nilai-nilai dan fakta (Mc Quail, 1991: 130).

Semua media mempunyai pedoman yang mengatur layak tidaknya sebuah berita ditayangkan. Pedoman ini mengacu Perundangan yang berlaku, seperti Undang-Undang Penyiaran, Kode Etik Jurnalistik, Peraturan KPI Tentang Pedoman Perilaku Penyiaran (P3) dan Tentang Standar Program Siaran (SPS).

Metro TV sebagai stasiun televisi juga mempunyai aturan-aturan yang mengatur layak tidaknya sebuah berita layak ditayangkan. Selain mengacu pada peraturan pemerintah, juga kepada Panduan Kebijakan \& Standar Berita yang dikeluarkan Metro TV tanggal 24 Agustus 2010. Panduan ini merupakan pegangan bersama dalam bekerja sehingga produk yang dihasilkan sesuai dengan standar yang digariskan dan akhirnya sesuai dengan harapan untuk menyajikan informasi yang bermanfaat bagi pemirsa.

Metro TV memiliki Standar Operasional Prosedur sendiri, dan itu sudah dipahami secara baik oleh semua pihak yang terlibat. Editing dilakukan berdasarkan standar etika dan norma sebagaiman diatur dalam UU Penyiaran, Kode Etik Jurnalistik, P3 dan SPS dari KPI.

Proses seleksi memilah-milah gambar yang ditayangkan yang dilakukan oleh seorang Editor. Dalam melaksanakan tugasnya seorang editor harus bekerja sama dengan reporter, cameraperson, asisten produser, produser, writer/staf produksi dan juga grafis.

Cameraperson harus menjadi filter pertama tentang gambar yang patut/ layak ditayangkan, jadi tidak asal mengambil gambar. Gam-

8 Wawancara dengan Suryopratomo (Direktur Pemberitaan Metro TV) tanggal 12 Juni 2012. 
bar kekerasan ditampilkan dalam kesempatan pertama dengan tujuan untuk memperlihatkan fakta namun penayangan gambar tersebut mesti dihindarkan dari upaya eksploitasi dan tidak boleh ditayangkan secara vulgar.

\section{SIMPULAN}

Dari segi ideologi, Metro TV merupakan stasiun televisi yang pertama di Indonesia yang menjadikan berita sebagai program utamanya dan menjadi Top of Mind sebagai sumber informasi utama bagi pencari berita. Kepentingan pemilik masih cukup kuat dalam mewarnai isi berita, berkaitan dengan keterlibatan pemilik menuju RI-1 tahun 2014. Munculnya TV berbayar telah membuat persaingan dalam meraih pemirsa kelompok $\mathrm{AB}$ semakin ketat. Metro TV dalam menghadapi persaingan tersebut berusaha merangkul kalangan muda (mahasiswa dan pelajar) dengan membuat program-program acara khusus seperti wideshot atau galau night dan kalau televisi swasta lain sangat mengandalkan rating dan share dalam menjaring pendapatan dari iklan, maka Metro TV lebih mengandalkan indeks.

Dari segi nilai-nilai budaya, Metro TV berkomitmen untuk mengurangi tayangan-tayangan tersebut dan akan lebih memberikan solusi dan penjelasan duduk perkara suatu peristiwa dan Metro TV secara khusus membuat program-program acara yang secara khusus mengangkat nilai-nilai budaya ke Indonesiaan sebagai bagian dari misi Metro TV untuk membangkitkan dan mempromosikan kemajuan Bangsa dan Negara

Dari segi etika, tayangan pornografi, kesadisan, identitas anak pelaku kejahatan, pemberitaan tidak berimbang dan pencampuradukan fakta dan opini, serta masalah suap merupakan bentuk pelanggaran etika yang terjadi dalam pemberitaan di Metro TV serta berbagai pelanggaran etika dalam pemberitaan di Metro TV menunjukkan pengawasan internal belum dilakukan secara maksimal.

Dari segi editor berita, cameraperson merupakan filter pertama dalam menyeleksi gambar yang patut atau layak ditayangkan, dan berita yang layak tayang di seleksi dan dievaluasi melalui rapat redaksi yang dilakukan sebanyak 3 (tiga) kali, yakni jam 06.00, 13.00, dan 19.00.

Sedangkan saran yang diajukan peneliti an- tara lain saran teoritis diantaranya (1) Penelitian ini hanya terfokus pada satu stasiun televisi, maka diharapkan ada kajian lebih lanjut bagi peneliti lain untuk mengkaji fenomena di stasiun televisi yang berbeda. (2) Stasiun televisi hendaknya tetap mengedepankan ideologi yang berpihak kepada masyarakat bukan ideologi yang mementingkan kelompok tertentu.(3) Berkenaan dengan televisi berbayar perlunya ada revisi undang-undang penyiaran yang mengatur kembali mengenai ketentuan jenis televisi ini. (4) Penggunaan indeks yang dilakukan Metro TV bisa dijadikan alternatif bagi media lain dalam menjaring pengiklan.

Sedangkan saran praktis yang diajukan peneliti dalam penelitian ini diantaranya (1) Nilai kearifan lokal tiap daerah di Indonesia seharusnya juga menjadi hal yang diperhatikan oleh stasiun televisi dalam menayangkan acaranya. (2) Budaya timur sebagai dasar etika berperilaku bagi masyarakat sebaiknya dipahami oleh para pekerja media, sehingga nilai etika ini tidak kebablasan dalam penayangan kekerasan, pornografi dan lain-lain. (3) Masih banyaknya tayangan yang berbau kekerasan, maka diharapkan pengelola media meminimalisir tayangan semacam ini. Pihak KPI dan pemerintah agar lebih waspada dan masyarakat agar lebih kritis terhadap tayangan ini. (4) Media hendaknya tetap menjunjung dan mematuhi pedoman perilaku penyiaran yang telah ditetapkan oleh KPI.

\section{DAFTAR PUSTAKA}

Amar, M. D. (1984). Hukum komunikasi jurnalistik. Bandung: Alumni.

Kitley, P. (2001). Kontruksi budaya bangsa di layar kaca. Jakarta: Institut Studi Arus Informasi.

Masduki dan Nazarudin, M. (2008). Media, jurnalisme dan budaya populer. Yogjakarta: Program Studi Ilmu Komunikasi UII dan UII press.

McQuail, D. (1991). Teori komunikasi massa, suatu pengantar. Jakarta: Erlangga.

---------.1992. Mass communication and the public interest. London-Newbury Park-New Delhi: Sage Publications.

Nielson. (2010). Nielsen audience measurement. Diakses 2011 dari http://www. google.com/url? sa=t\&rct=j\&q=\&es $\mathrm{rc}=\mathrm{s} \& \mathrm{~s}$ ource $=$ we b $\& \mathrm{~cd}=1 \& \mathrm{ved}=0 \mathrm{C}-$ 
CcQFjAA\&url=http $\% 3 \mathrm{~A} \% 2 \mathrm{~F} \% 2 \mathrm{Fxa}$. $\mathrm{y}$ i $\mathrm{m} \mathrm{g}$. c o m \% $2 \mathrm{~F} \mathrm{k} \mathrm{q} \mathrm{\%} 2 \mathrm{~F}$ groups $\% 2 \mathrm{~F} 18720442 \% 2 \mathrm{~F} 1318505660 \% 2 \mathrm{~F}-$ name $\% 2$ FNielsen $\% 2$ BPress $\% 2$ BRe1 e a s e - N e w s_A pri $1 \% 2$ B 2010 . pdf\&ei=0ntUU7DnN8S_rgfGzYGAAw\&us$\mathrm{g}=\mathrm{AFQjCNFVnf2GBBJ3xRj9TcWctsL0t-}$ WRUqA\&bvm=bv.65058239,d.bmk.

Ratna, N. K. (2010). Metode penelitian, kajian budaya dan Ilmu Sosial Humaniora pada umumnya. Yogjakarta: Pustaka Pelajar.

Ritzer, G. \& Smart, B. (2011). Handbook teori sosial. Terjemahan Imam Muttaqien, Derta Sri dan Waluyati. Bandung: Nusa Media.
Rivers, W. L., dan Mathews, C. (1994). Etika media massa, dan kecenderungan untuk melanggarnya. Terjemahan Arwah Setiawan dan Danan Priyatmoko. Jakarta: Gramedia Pustaka Utama.

Subandy, I. (2007). Budaya populer sebagai komunikasi, dinamika popscape dan mediascape di Indonesia kontemporer. Jogyakarta: Jalasutra.

Sunarto. (2009). Televisi, kekerasan \& perempuan. Jakarta: Kompas Media Nusantara.

Metro TV. (2010). Panduan kebijakan \& standar berita. 